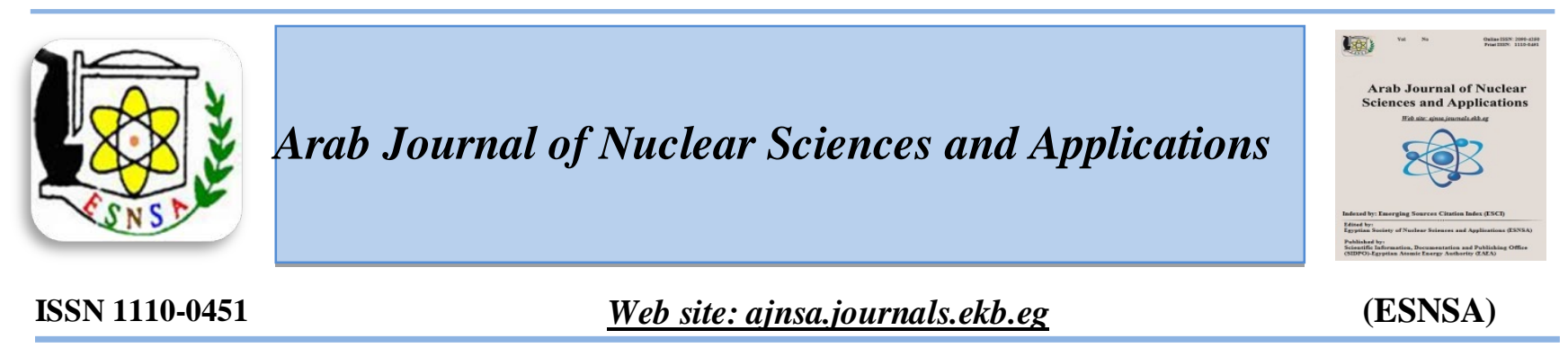

\title{
Structural and Thermal Analysis of Carbon Nano-Particles/Polypyrrole/Poly (Ethylene - Co - Vinyl Acetate) Composites
}

\author{
R. M. Ahmed ${ }^{(1)}$ and A. M. Abd Elbary ${ }^{(2)}$ \\ ${ }^{1}$ Physics Department, Faculty of Science, Zagazig University 44519, Zagazig, \\ ${ }^{2}$ Department of Mathematics and Physical Science, Higher Institute of Engineering and Technology \\ New Cairo Academy, Cairo, Egypt
}

\begin{abstract}
Received $21^{\text {st }}$ Jan. 2018 Polymeric materials and their composites have attracted an increasing attention because of their great Accepted $3^{\text {rd }}$ June 2018 significance. This study includes the preparation of composites of carbon nano-particles/Polypyrrole (CB/PPY) embedded in Ethylene-vinyl acetate copolymer (EVA) with different contents of 0, 5, 10, 15, 20 and 30 parts per hundred parts by weight of polymer (pph). X-ray diffraction (XRD) was utilized to characterize the structure of the prepared composites. Thermal analysis including differential scanning calorimetry (DSC) and thermogravimetric analysis (TGA) were carried out to detect the miscibility degree of the composites and their thermal stability. The Gordon - Taylor equation was modified to fit the experimental values of the glass transition temperatures $\left(T_{g}\right)$ at low and high contents of CB/PPY. The obtained values of $T_{g}$ showed complete miscibility of most of the composites. From XRD measurements, the crystallinity of the composites was found to be decreased by embedding (CB/PPY) into EVA. The curves of TGA show more thermal stabilities for the composites compared to the pristine EVA.
\end{abstract}

Keywords: DSC, TGA, XRD, EVA, Carbon black, PPy

\section{Introduction}

To acquire composites with modified physical properties to be applicable in industry, polymer blending and/or additive with filler can be promising candidates for this purpose. DSC and TGA techniques are widely used to measure the thermal properties and the blending polymers and embedding them with filler [1]. Homo-polymers, copolymers and also polymer blends can be characterized by a significant parameter known as glass transition temperature $\left(\mathrm{T}_{\mathrm{g}}\right)$ obtained by DSC measurements [2]. Transferring from glassy state to rubbery state does not occur_abruptly but gradually, so it is better to describe $\left(T_{g}\right)$ as glass transition region instead of glass transition temperature. The gradualism from glassy state to rubbery state means that the phenomenon of $\left(\mathrm{T}_{\mathrm{g}}\right)$ covers broad temperature windows but the experimentalists prefer to report only a single value of $\left(\mathrm{T}_{\mathrm{g}}\right)$ to facilitate comparisons between different binary polymer blend concentrations [3]. Determining $\left(\mathrm{T}_{\mathrm{g}}\right)$ values of the polymer blend, enables knowing its state of being immiscible or compatible or fully miscible (single value of $\mathrm{T}_{\mathrm{g}}$ ) [4]. Characterizing the structure and understanding the possible physical properties that occur at the interface of materials can be investigated by (XRD). XRD is considered as the main technique in evaluating the crystallinity index and also

Corresponding author: rania.7.8.2016@gmail.com

DOI: 10.21608/ajnsa.2018.2715.1046

(C) Scientific Information, Documentation and Publishing Office (SIDPO)-EAEA 
analyzing the structure of polymer blends and nanocomposites [5].

Carbon-based polymers are considered as insulators. This makes these materials good candidates for use in the electronic industry. Interestingly, carbon nanoparticles as well as conducting polymers (CPs) have exhibited novel and wonderful properties. Novel multifunctional materials, employed in different applications, have been created from composing CPs with carbon nanoparticles. Low cost, excellent conductivity, high physicochemical stability are some features that enable Polypyrrole (PPy) to be one of the most important conductive polymer which are applied as batteries, conductive fibers, gas sensors, super capacitors and photovoltaic cells [6,7]. Nevertheless, PPy suffers from poor strength and insolubility; therefore PPy is included in blend or composite preparation to overcome these limitations [8].

This work is concerned with studying the structure and thermal analysis of $\mathrm{CB} / \mathrm{PPy}$ embedded in ethylene-vinyl acetate copolymer (EVA) to form composites of different components. EVA is a random copolymer created from ethylene monomer and vinyl acetate (VAc) where the ratio of the two components play an important role in modifying the properties of EVA. In this regard, EVA becomes further akin to polyethylene and being able to crystal when the content of (VAc) is low, whereas with a high content of (VAc), the polyethylene chains packing in the crystal lattice are averted because of the extreme pendent acetoxy [1]. Kamath and Wakefield [1] have reported that $43 \%$ by weight of (VAc) content can produce amorphous and rubber-like EVA. Because of its low cost, excellent barrier and electrical properties, EVA has been used in different applications as corrosion protection, encapsulation and many other engineering plastics [9].

In the present work, the main objective is to modify the thermal properties of EVA. The miscibility of CB/PPy with EVA was examined through DSC measurements and the values of $T_{g}$ of their composites were estimated theoretically and compared with the experimental one. It was so important in this work to test and modify different theoretical models to fit the experimental values of $\mathrm{T}_{\mathrm{g}}$ of the composites depending on the content of
CB/PPy. The effect of CB/PPy content on the crystalline microstructure of the hosting polymer was studied by XRD. The crystallinity, the grain size and some other parameters were deduced from the XRD pattern to get more information about the hosting polymer (EVA) structure changes in its different composites. The thermal stability was also tested for the prepared samples from the TGA analysis.

\section{Experimental Details}

Materials and preparations of samples

Both EVA (12\% VA), in the form of pellets and carbon nano-particles / Polypyrrole (CB/PPY) were purchased from Aldrich Company. EVA was melt-mixed at a temperature of $80^{\circ} \mathrm{C}$, and a speed of $80 \mathrm{rpm}$ for 5 minutes. Then CB/PPY was added and the mixing lasted for another swing. CB/PPY was mixed with EVA with different contents of 0 , 5, 10, 15, 20 and 30 parts per hundred parts by weight of polymer (Php). The resultant mixtures were sheeted on a two roll mill at $60^{\circ} \mathrm{C}$. The produced sheets were compression molded between smooth Teflon sheets at a temperature of $110^{\circ} \mathrm{C}$ and a pressure of $5(\mathrm{MPa})$ in an electrically heated press (type carver M-154). To ensure predetermined sheet size, the hot pressed sheet was cold pressed afterward in another press at the same pressure and cooled with water.

\section{Thermal analysis}

Differential Scanning Calorimetry (DSC) and Thermal Gravimetric Analysis (TGA) measurements were effective tools for analyzing thermally EVA and its composites with (CB/PPy).

\section{DSC Measurement}

Differential Scanning Calorimeter model Shimadzu DSC-50 was used to investigate the behavior of thermal transition for all samples in a range of temperatures from $-50^{\circ} \mathrm{C}$ to $350{ }^{\circ} \mathrm{C}$. The scanning was examined under nitrogen atmosphere at a heating rate $10^{\circ} \mathrm{C} / \mathrm{min}$ and an average weight of $1.75 \pm 0.501$ (mg).

\section{TGA Measurement}

TGA was carried out using a Shimadzu TGA-50 Thermo gravimetric analyzer. The measurements were taken under an atmosphere of nitrogen with a flow rate of $30 \mathrm{ml} / \mathrm{min}$, at temperatures between 20 and $550^{\circ} \mathrm{C}$ and a heating rate of $10^{\circ} \mathrm{C} / \mathrm{min}$. The 
initial weight of the samples was around 10-11mg for each one.

\section{XRD Measurement}

The samples were characterized by XRD, with $\mathrm{Cu}$ $\mathrm{K} \alpha$ radiation $\left(\lambda=1.5405^{\circ} \mathrm{A}\right)$ (type Philips X'Pert Diffractometer) and a scan rate of 2.5 (degree/min). The measurements were examined in a scan range from $15^{\circ}$ to $80^{\circ}$.

\section{Results and Discussion}

\section{DSC Analysis}

Information about the values of $T_{\mathfrak{g}}$, melting point $\left(\mathrm{T}_{\mathrm{m}}\right)$ and their enthalpies $(\Delta \mathrm{H})$ can be determined by analyzing DSC curve. Figure1 illustrates DSC curves of pristine EVA and its composites with CB/PPy. A step transition was detected in which its midpoint in this case is corresponding to the glass transition temperature of the composites. The determined values of $\mathrm{T}_{\mathrm{g}}$ were in the temperature range from $54.09{ }^{\circ} \mathrm{C}$ to $57.8{ }^{\circ} \mathrm{C}$ for both of the pristine EVA and the highest content of $\mathrm{CB} / \mathrm{PPy}$ embedded in EVA, respectively.

Generally, in a miscible blend, the value of $\mathrm{T}_{\mathrm{g} 1}$ of one homopolymer changes towards the value of the $T_{\mathrm{g} 2}$ of the other. However, the glass transition of a homopolymer in an immiscible blend remains approximately as its bulk value regardless of the composition [10]. In this study, the composition glass transition temperature has nearly the same value of the hosting polymer (EVA), as seen in Table (1) which gives an indication of complete miscibility of the composites, except for the composite with 20 (pph) which has a considerable change in its $\mathrm{T}_{\mathrm{g}}$.

Due to the importance of glass transition phenomenon, many approaches have already been investigated, based on thermodynamic or kinetic features of $T_{g}$, to consider a theoretical base for models presently used to estimate $\mathrm{T}_{\mathrm{g}}$ of binary polymer blends from knowledge of properties of their homopolymers $[3,11]$. One of these models is the Fox equation for a binary system 1 and 2 [4, 12]:

$$
\frac{1}{T_{g}(\text { Fox })}=\frac{w_{1}}{T_{g 1}}+\frac{\left(1-w_{1}\right)}{T_{g 2}}
$$

Where $T_{g}$ pertains to the blend, $T_{g i}$ is corresponding to the component $i$ and $\mathrm{w}_{\mathrm{i}}$ is the mass (weight fraction) of the component $i$ in which $w_{2}=1-w_{1}$. Another way to estimate $T_{g}$ of a binary polymer blend is by Gordon Taylor (GT), Eq. 2:

$$
T_{g}(G T)=\frac{w_{1} T_{g 1+}\left(1-w_{1}\right) k_{G T} T_{g 2}}{w_{1}+\left(1-w_{1}\right) k_{G T}}
$$

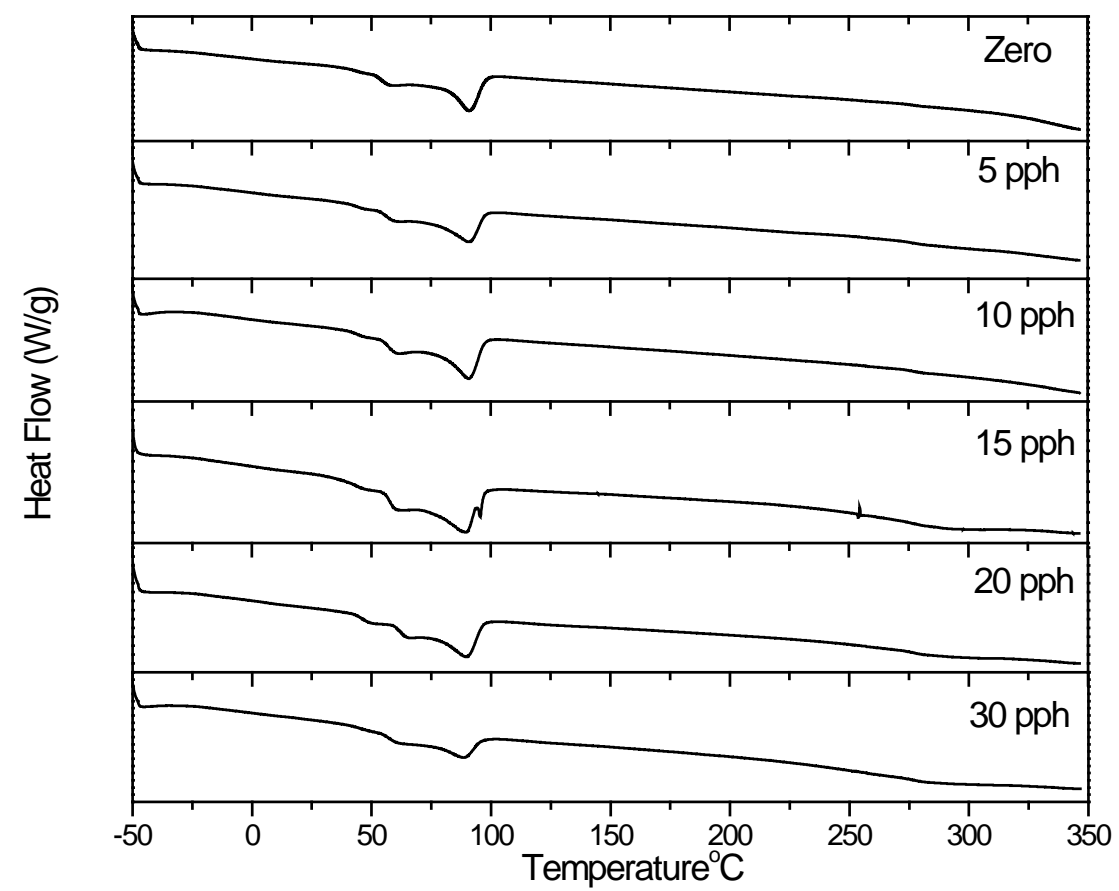

Figure (1) DSC curves of different contents of CB/PPY (pph) embedded in EVA 
Where $\mathrm{k}_{\mathrm{GT}}$ is a parameter estimated from the experimental data and it represents unequal contributions of constituent to the blend. Figure (2) illustrates a comparison between the experimental and the estimated theoretical values of $T_{g}$ of the composites by using EVA $\left(\mathrm{T}_{\mathrm{g} 1}=54.09^{\circ} \mathrm{C}\right)$ and the corresponding values of $\mathrm{CB} / \mathrm{PPy}\left(\mathrm{T}_{\mathrm{g} 2}=105^{\circ} \mathrm{C}\right.$ as measured in the lab and is not included here). These results seem plenty for manifestation of utility of Fox and Gordon Taylor equations up to the highest contents of CB/PPy embedded in EVA (20 and $30 \mathrm{pph}$ ) where it fails. In other words, Fox and Gordon-Taylor equations can be satisfactory in "very well behaving" miscible/partial miscible system for low CB/PPy content [4]. It was essential to modify the Gordon Taylor equation to fit the highest values of the CB/PPy. The parameter $\mathrm{k}_{\mathrm{GT}}$ in Gordon Taylor equation could be replaced by the polynomial fit equation which describes the dependence of $\mathrm{T}_{\mathrm{g}}$ on the mass fraction of the component as following:

$$
\begin{aligned}
& T_{g}\left(G T_{\text {modified }}\right)= \\
& \frac{w_{1} T_{g 1+}\left[b_{o}+b_{1}\left(1-w_{1}\right)+b_{2}\left(1-w_{1}\right)^{2}+b_{3}\left(1-w_{1}\right)^{3}\right]\left(1-w_{1}\right) T_{g 2}}{w_{1}+\left(1-w_{1}\right)\left[b_{o}+b_{1}\left(1-w_{1}\right)+b_{2}\left(1-w_{1}\right)^{2}+b_{3}\left(1-w_{1}\right)^{3}\right]}
\end{aligned}
$$

Where $b_{0}=1.6196, b_{1}=-23.84995, b_{2}=160.43272$ and $b_{3}=-322.719$. Figure 2 illustrates the validity of the modified equation of Gordon Taylor for low as well as high contents CB/PPy compared with both the Fox and unmodified Gordon- Taylor equations.

Alternatively, the heat flow rate into the sample is obtained from the following relation [13]:

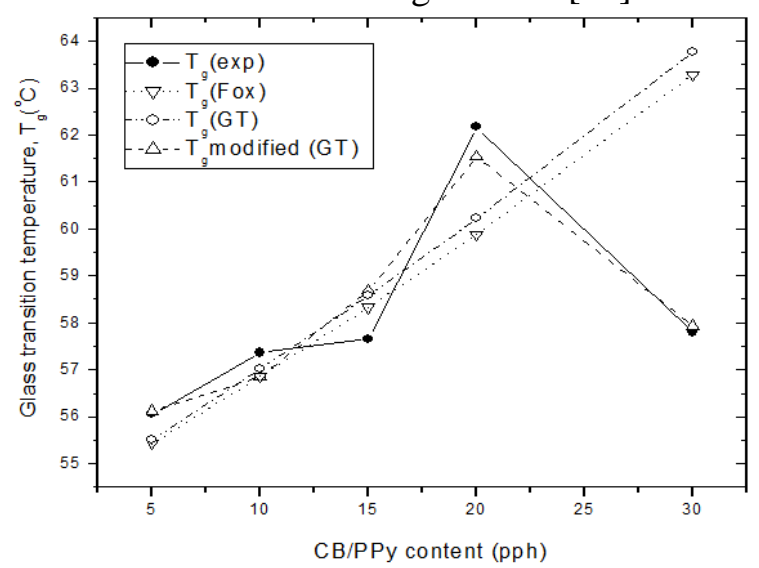

Figure (2) For CB/PPY and EVA depending on composition, the estimated values of $T_{g}$ from (•) experimental measurements, $(\nabla)$ Fox equation, calculated by equation 1, $(\diamond)$ Gordon Taylor equation, calculated by equation 2 and $(\Delta)$ modified Gordon Taylor equation, calculated by equation 3 . $\frac{d H}{d T}=m C_{p} \frac{d T}{d t}$

Where $C_{p}$ is the specific heat in $\left(\mathrm{J} / \mathrm{g}{ }^{\circ} \mathrm{C}\right), \frac{d H}{d T}$ is the heat flow rate in (J/gram.sec), $m$ is the mass of the sample (in grams) and $\frac{d T}{d t}$ is the heating rate in $\left({ }^{\circ} \mathrm{C} / \mathrm{sec}\right)$. The calculated values of $C_{p}$ are given in Table (1). It is illustrated that increasing the content of (CB/PPY) embedded in EVA causes a decrease in the values of the specific heat $\left(C_{p}\right)$ for the composites. This may be attributed to the role of the embedded (CB/PPy) that can inhibit the cooperative motion of an amorphous matrix part and consequently it does not allow this part to contribute in the $T_{g}$ phenomenon [14]. Recognizing the purity degree of a specimen and its nature can be provided by determining an endothermic melting point temperature which shows a change in its shape and area under endotherm depending on the nature of the tested material. Examining the extent to which CB/PPy content could affect the crystallization and $\mathrm{T}_{\mathrm{m}}$ of the pristine EVA and composites were comprehend during heating process of DSC measurement.

The characteristic data obtained from DSC curves including, peak of melting temperature $\left(\mathrm{T}_{\mathrm{m}}^{\mathrm{P}}\right)$, final melting temperature $\left(\mathrm{T}_{\mathrm{m}}^{\mathrm{f}}\right)$, melting enthalpy $\left(\Delta \mathrm{H}_{\mathrm{m}}\right)$ and the crystallinity degree on melting $\left(X_{m}\right)$ are summarized in Table 1. Figure(3) illustrates an obvious decrease in the values of final $\left(\mathrm{T}_{\mathrm{m}}^{\mathrm{f}}\right)$ and peak $\left(\mathrm{T}_{\mathrm{m}}^{\mathrm{P}}\right)$ melting temperature by increasing CB/PPy content of all composites. This behavior can be deduced from the slopes of these melting temperatures against the CB/PPy content while they are approximately parallel to each other.

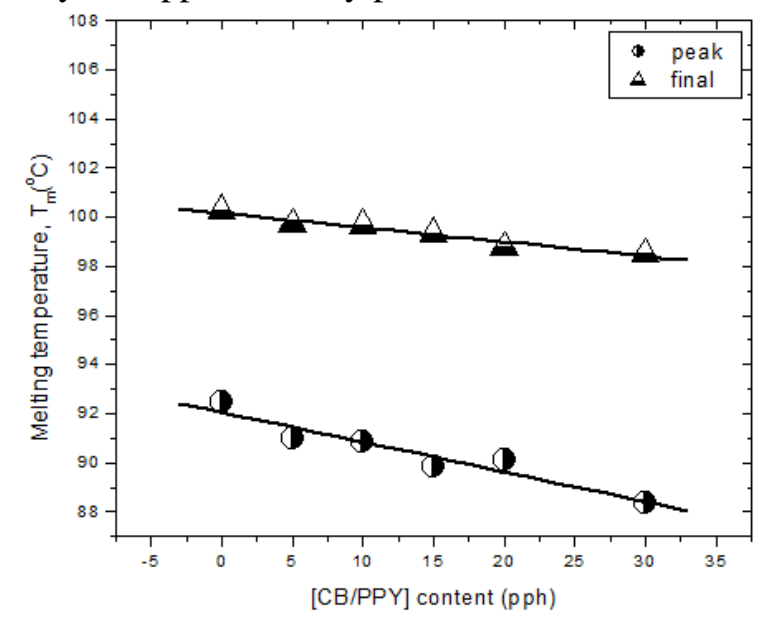

Figure (3) The peak and final values of melting point, $T_{m}$ of different contents of CB/PPy embedded in EVA 
Generally, linear polyethylene has the ability to be crystallized from its melt into lamellar structures. The melting temperature of these lamellar crystals is depressed below the equilibrium melting because of being extremely thin. Consequently, the distribution of the lamellar thicknesses in a crystallized sample can be known from the detected melting point [15]. So, the observed decrease in the $T_{m}$ by increasing the CB/PPY content in EVA can be a result of decreasing the thickness of lamellar. This result can be verified from Figure1 which shows that EVA with the highest melting temperature $\left(\mathrm{T}_{\mathrm{m}}^{\mathrm{P}}=92.48^{\circ} \mathrm{C}\right)$ is the sharpest among all the composites. The wide range of $\mathrm{T}_{\mathrm{m}}$, which results in obtaining a wide size distribution of the crystallities ${ }^{1}$ by increasing the $\mathrm{CB} / \mathrm{PPy}$ content in EVA, was a reason of incapability of detecting the onset $T_{m}$.

One of the most important essential thermodynamic properties of materials is the enthalpy $(\Delta \mathrm{H})$ which is known to be temperature dependent and the altering of its value due to phase change is also a temperature dependent [16]. The enthalpy change $(\Delta \mathrm{H})$ can be determined for a phase transition by integrating over the area in which this transition takes place on the DSC curve [17]. From Table 1, it can be seen that the magnitude of the integrated melting temperature peak gives melting enthalpy, $\Delta \mathrm{H}_{\mathrm{m}}$ for EVA to be $33.02(\mathrm{~J} / \mathrm{g})$ which decreased to be $13.78(\mathrm{~J} / \mathrm{g})$ for the highest CB/PPy content 30 (pph) embedded in EVA. The crystallinity $\left(X_{m}\right)$ on melting was calculated for all samples using the following relation [17]:

$X_{m}=\frac{\Delta H_{m}}{f \cdot \Delta H_{m}^{o}} \times 100 \%$

Where (f) is the weight fraction of CB/PPy into the composite and $\Delta H_{m}^{o}$ is the melting enthalpy of $100 \%$ crystalline of EVA $14(63.9 \mathrm{~J} / \mathrm{g})$ as reported previously [1]. The tabulated values of $\left(X_{m}\right)$ as observed in Table 1 were affected by CB/PPy content in which $\left(X_{m}\right)$ was decreasing by increasing its content in EVA. The attitude of $\left(\Delta \mathrm{H}_{\mathrm{m}}\right)$ is correlated to that of $\left(X_{m}\right)$ as both of them was CB/PPy content dependent.

\section{Themogravimetric analysis (TGA)}

Thermal degradation behavior of EVA and its composites with CB/PPY was examined by TGA as shown in Figure4. The pristine EVA and its composite embedded by the highest content of
CB/PPY show weight loss of $12.76 \%$ and $15.84 \%$, respectively, in the first stage that started at $180^{\circ} \mathrm{C}$ then followed by thermal stability at the second stage. More significant weight loss of $85.2 \%$ and $65.67 \%$ were determined for EVA (above $380^{\circ} \mathrm{C}$ ) and its composite embedded by the highest content of CB/PPY (above $420^{\circ} \mathrm{C}$ ), respectively.

The TGA curves for EVA as well as its composites are also shown in Figure4. Obviously, the recorded themogravimetric plots for all samples show clearly two degradation regions which suggest the coexistence of more than one degradation process. All tested samples show weight loss of (12.76 15.84) \% for the first decomposition stage and more significant a weight loss $(85.2-65.67) \%$ for the second decomposition stage. The change in weight loss reaches its maximum value for pristine EVA while the value of its composite embedded by the highest content of CB/PPy shows the minimum decomposition. This means that the composite of 30 (Php) of CB/PPy embedded in EVA shows more thermal stability.

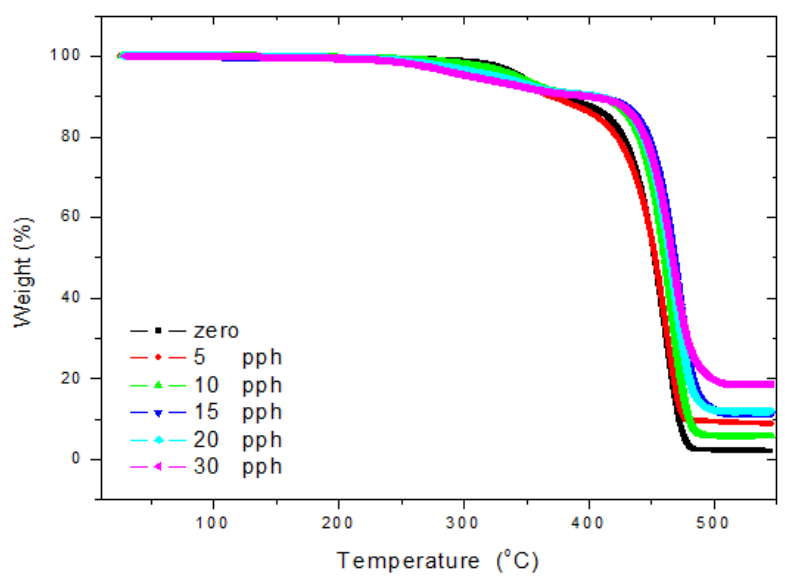

Figure(4) TGA thermograms of EVA embedded with CB/PPy (pph)

The lower values of weight loss \% in the first stage can be attributed to the presence of a thermal process due to moisture evaporation from samples. This behavior can be ascribed to splitting or volatilization of small molecules in which weight loss varies between $12.76 \%$ and $15.84 \%$ and begins at $\approx 200^{\circ} \mathrm{C}$. This lower value of weight loss may suggest that the transitions observed in the corresponding temperature range of the earlier discussion of DSC spectra can explain the existence of a physical transition [18].

Arab J. Nucl. Sci. \& Applic. Vol. 51, No. 4 (2018) 
The TGA curves cover a wider temperature range $\left(180^{\circ} \mathrm{C}-550^{\circ} \mathrm{C}\right)$, which includes the melting points as a physical transition and the degradation temperatures of homo polymers. Therefore, the higher values of weight loss in the second decomposition stage indicate the existence of a chemical degradation process resulting from bond scission (carbon-carbon bonds) in the polymeric backbone. The degradation behavior of the composites is an intermediate between that of the pure components. It must be noted that the sample of composition 15 (pph) of CB/PPy embedded in EVA presents a high strength of bonding due to crosslink formation, since little amounts of weight loss in the first decomposition region are recorded. Above this concentration, the compositions become more thermally stabile and the maximum loss was observed at a temperature of $\approx 470^{\circ} \mathrm{C}$ which is greater than the corresponding temperature for one of the pristine EVA by about 9 ${ }^{\circ} \mathrm{C}$.

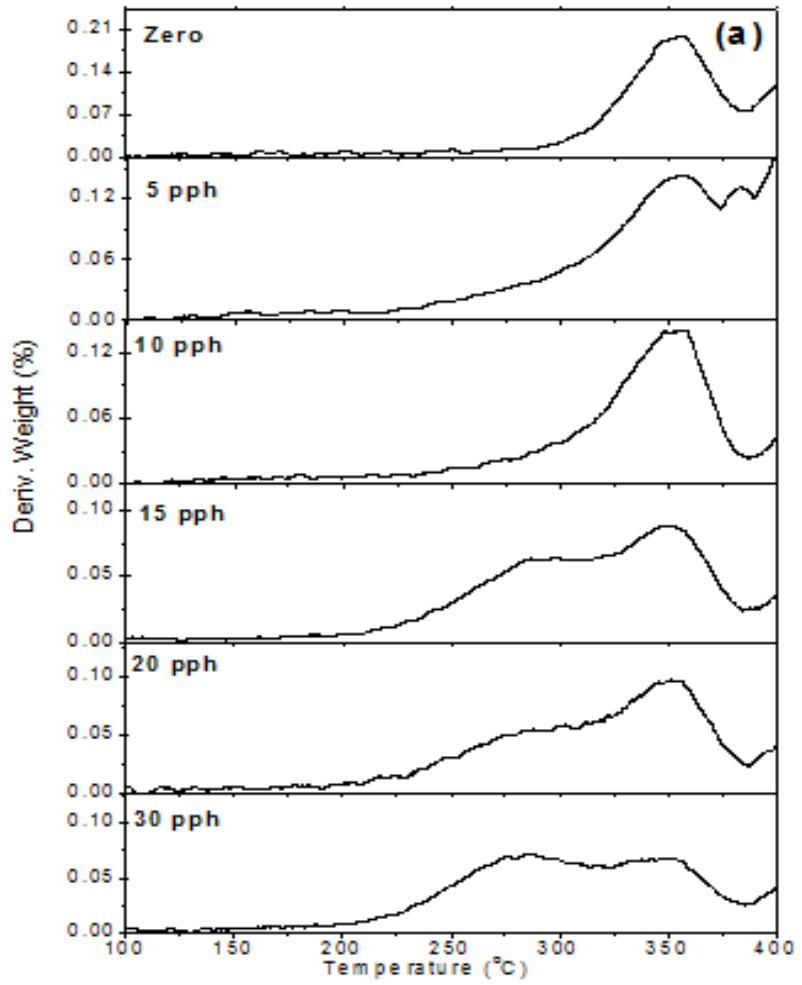

The difference in the thermal decomposition behavior of EVA and its composites with CB/PPy can be understood from the derivative thermogravimetric (DTGA) curves as shown in Figure(5). DTGA curves show broad and sharp peaks corresponding to the first and second decomposition regions, respectively. It was observed that, the peak temperatures of DTGA curves in both decomposition regions of the composites was affected by increasing CB/PPy content embedded in EVA, as seen in Table (2). This behavior indicates that the thermal stabilities of EVA were enhanced by increasing the embedded content of CB/PPy. This stability can suggest the capability of using the composites in commercial applications for item production via melt processing techniques. Figure(6) shows the relation between residue (\%) and CB/PPy content. One can see that the residue (\%) increases up to the composition of 5 (pph) of CB/PPy then it decreases followed by a nearly stabilization region then it starts to increase for CB/PPy content $\geq 20$ (pph).

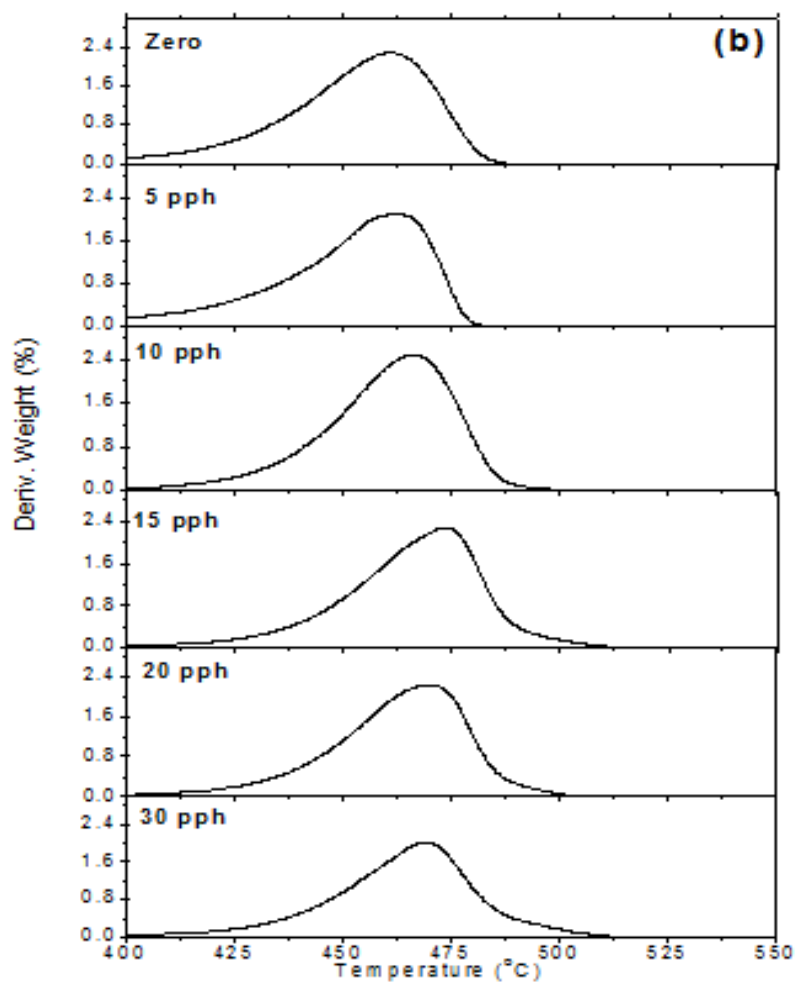

Figure (5) DTGA thermograms of EVA and its composites with CB/PPy in a range of temperature (a) from 100 to $400^{\circ} \mathrm{C}$ and (b) from 400 to $550{ }^{\circ} \mathrm{C}$ 


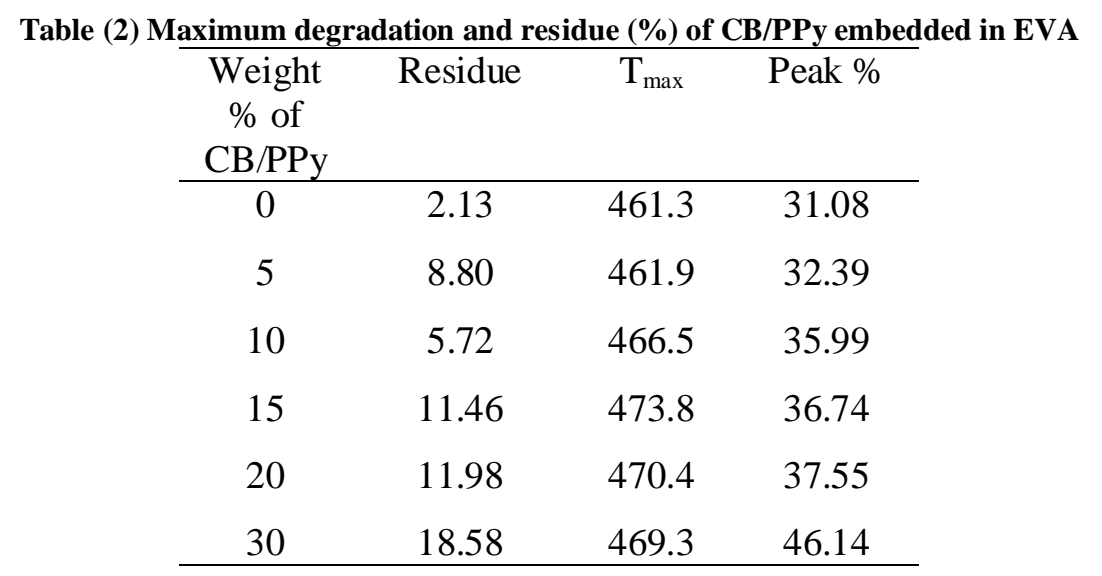

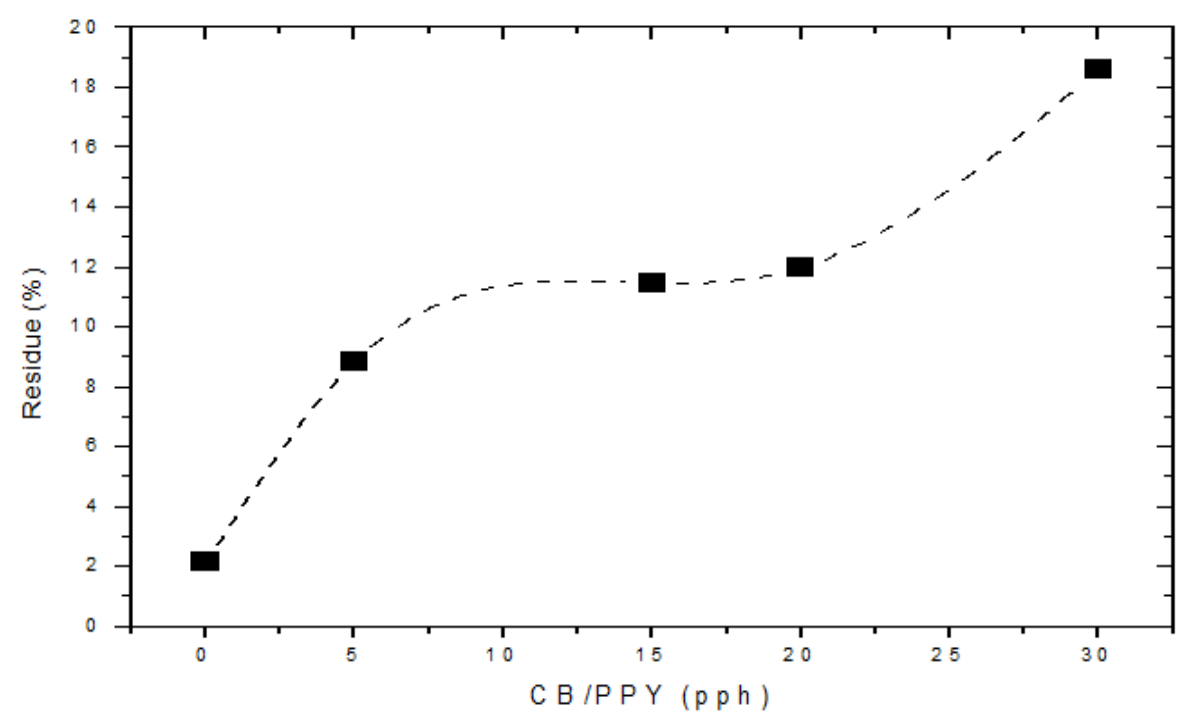

Figure (6) The relation between residue (\%) and CB/PPy content embedded in EVA

\section{$X$-Ray diffraction analysis}

Polymers are not completely crystalline as they do not have a wholly ordered crystal lattice because they contain both amorphous and crystalline regions. Therefore, the pattern of XRD is expected to be formed from both diffused (amorphous region) and sharp patterns (crystalline region) [19]. Considering the XRD analysis shown in Figure(7), one notes that the position in $2 \theta$ of every probable Bragg reflections are shown in the XRD pattern of pristine EVA and its composites with different contents of CB/PPy. The appearance of the peaks at $2 \theta$ of $21.6 \pm 0.15^{\circ}$ and $23.8 \pm 0.19^{\circ}$ is attributed to the scattering polypyrrole chains at the interplanar spacing according to the previous literature [20]. The broad X-ray peaks indicate the high disorder of PPy matrix and also that the chains of PPy have short range arrangement [21].

Additionally, the X-ray spectra showed a strong reflection peak at $2 \theta=16.9^{\circ}$, which is characteristic to EVA, and this was also present in all composites around the same angle [22]. For all EVA containing composites, the XRD patterns showed a peak at $2 \theta=21.5^{\circ}$ related to the crystalline region of EVA, while a weak peak at $2 \theta$ $=23.64^{\circ}$ was assigned to its amorphous region. The positions of these peaks which are characteristic EVA did not shift significantly compared to the corresponding peaks in the composites. This confirms that creation of composites by addition of CB/PPy to EVA did not change the crystalline structure of the hosting polymer EVA [23].

In this study, it was found that CB shared its characteristic peak, centered approximately at $2 \theta$ of $23.8^{\circ} \pm 0.19$ with both of PPy and EVA, for all composites [24]. For all the components of the composites, their main characteristic peaks of the 


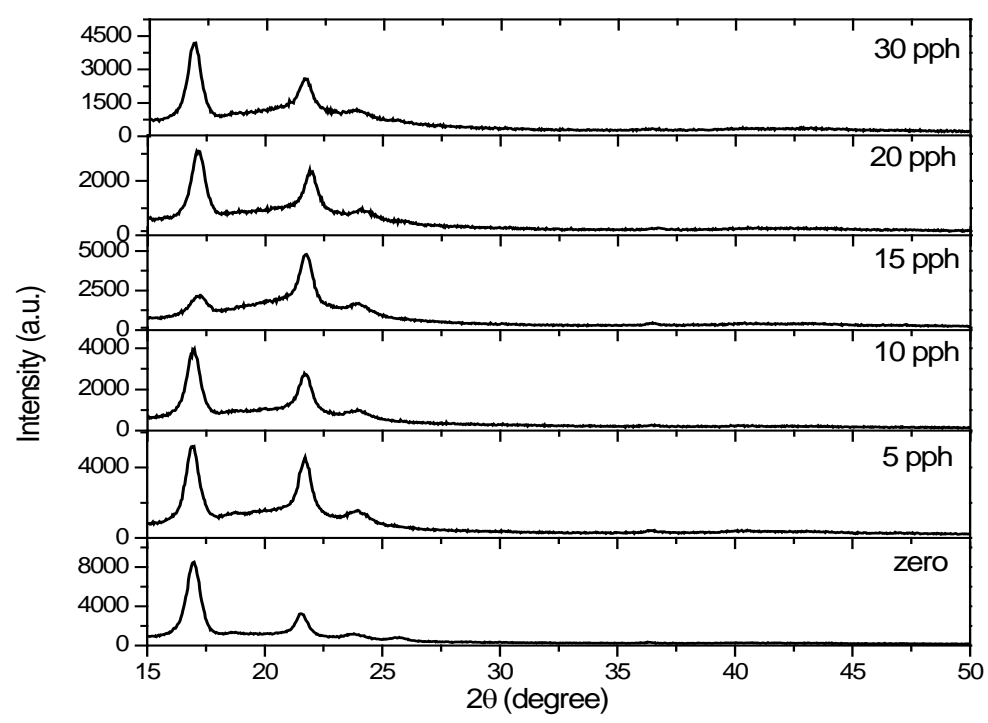

Figure (7) X-ray diffraction pattern of different contents of CB/PPy embedded in EVA

XRD pattern located at $2 \theta$ of $16.9 \pm 0.16(012)$, $21.6 \pm 0.15$ (022) and $23.8 \pm 0.19$ (113) which have d-spacing of 5.241, 4.129, and $3.760{ }^{\circ} \mathrm{A}$, respectively, and Lattice constant, a, of 11.719, 11.678 and $12.471^{\circ} \mathrm{A}$, respectively.

In this study, it was found that CB shared its characteristic peak, centered approximately at $2 \theta$ of $23.8^{\circ} \pm 0.19$ with both of PPy and EVA, for all composites [24]. For all the components of the composites, their main characteristic peaks of the XRD pattern located at $2 \theta$ of $16.9 \pm 0.16$ (012), $21.6 \pm 0.15$ (022) and $23.8 \pm 0.19$ (113) which have d-spacing of 5.241, 4.129, and $3.760{ }^{\circ} \mathrm{A}$, respectively, and Lattice constant, a, of 11.719 , 11.678 and $12.471^{\circ} \mathrm{A}$, respectively.

The crystallinity fraction of the grain was deduced from the ratio of integrated area of crystalline peak $\left(A_{c}\right)$ to the total integrated areas of all peaks $\left(A_{\text {total }}\right)$ according to the following equation [25]:

$\chi(\%)=\frac{A_{c}}{A_{\text {total }}} \times 100$

The values of $\chi(\%)$, as shown in Table (3), showed CB/PPy content dependence, in which $\chi$ (\%) is decrease by the addition of CB/PPy. Moreover, a decrease in the relative intensities of these characteristic peaks of composites by increasing the content of $\mathrm{CB} / \mathrm{PPy}$ embedded in EVA, as seen in Figure(8), can be understood as a decrease in their overall crystallinity [23].
The average grain sizes $(\mathrm{D}$, in $\mathrm{nm})$ of all samples were calculated according to the well known Debye Scherrer formula [26,27]:

$D=\frac{k \lambda}{B(\cos \theta)}$

Where $\lambda$ is $\mathrm{X}$-ray wavelength, $\mathrm{B}$ is the full width at half maximum (FWHM, in radian), $\theta$ is the Bragg angle and $\mathrm{k}$ is the Scherrer factor which equals to 0.9 and it also depends on the Miller index of the reflecting crystallographic planes and the shape of crystallite as well as crystal [28]. The dislocation density $(\delta)$, described as the length of dislocation lines per unit volume, which represents effectively the amount of defects in the studied samples [29], was estimated from Williamson and Smallman's equation [27]:

$\delta=\frac{1}{D^{2}}$

The estimated values of $\mathrm{D}$, as seen in Table (3), show that the grain size decreases with increasing the extent of embedding CB/PPY in EVA while preparing the composites. This can be attributed to the fact that the mobility of the grain boundaries affects effectively the grain growth. Therefore, embedding EVA with nanoparticles of CB/PPy can reduce the grain size due to the decrease the grain growth [30]. In other words, the addition of CB/PPy to EVA can increase the broadness of XRD peaks (see Table 3) which lead to the nanocrystalline feature of the prepared film [29]. Therefore, the grain size (D) was decreased from $15.18 \pm 0.86(\mathrm{~nm})$ corresponding to EVA to be 
$10.92 \pm 1.29(\mathrm{~nm})$ for the highest content of CB/PPy in the composite. On the other hand, Table (3) illustrates an increase in the discerned values of ( $\delta$ ) by increasing the $\mathrm{CB} / \mathrm{PPy}$ content.

The observed broadening in the XRD peak can be attributed to the strain as well as the crystallite size of the particles. Therefore, there was a trial to discern the lattice strain $\left(\varepsilon_{\text {str. }}\right)$ of the prepared sample using the relation of Stokes-Wilson [31]:

$\varepsilon_{\text {str }}=\frac{B}{4(\tan \theta)}$

Table (3) illustrates the increase of the lattice strain values by increasing the embedded content of CB/PPy.

\section{Conclusion}

Different composites of $\mathrm{CB} / \mathrm{PPy}$ embedded in EVA were prepared in varying ratios. Alternative techniques were investigated to characterize and understanding the structure and thermal stability of the produced composites. DSC measurements illustrated a decrease in the values of specific heat, melting enthalpy and the crystallinity of the composites by increasing CB/PPy content. The Gordon - Taylor equation was modified to fit the experimental values of the $T_{g}$ at low and high contents of CB/PPy. The calculated values of lattice strain and the dislocation density obtained from XRD curves were found to increase by increasing the CB/PPy content, whereas the average grain sizes as well as crystallinity fraction were decreased. TGA analysis provided information about the enhancement of the thermal stability of the composites compared to the pristine EVA which can enable suggesting such composites to be applied in various technological applications.

Table (3) The values of full width at half maximum (F WHM), lattice strain ( $\left.\varepsilon_{\mathrm{str}}\right)$, average grain sizes (D), dislocation density $(\delta)$, crystallinity fraction of the $\chi(\%)$.

\begin{tabular}{|c|c|c|c|c|c|c|c|}
\hline \multirow{2}{*}{ 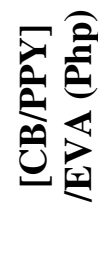 } & \multicolumn{3}{|c|}{ FWHM (degree) } & \multirow{2}{*}{$\varepsilon_{\text {str. }}$} & \multirow{2}{*}{$\begin{array}{c}\mathbf{D}_{\text {average }} \\
\text { Shererr } \\
(\mathrm{nm})\end{array}$} & \multirow{2}{*}{$\begin{array}{c}\boldsymbol{\delta} \\
\left(10^{15}\right. \\
\left.\text { lines } / \mathrm{m}^{2}\right)\end{array}$} & \multirow{2}{*}{$\begin{array}{c}\chi \\
(\%)\end{array}$} \\
\hline & $\begin{array}{c}2 \theta= \\
16.9 \pm \\
0.16\end{array}$ & $\begin{array}{c}2 \theta= \\
21.6 \\
\pm 0.15\end{array}$ & $\begin{array}{c}2 \theta= \\
23.8 \\
\pm 0.19\end{array}$ & & & & \\
\hline $\mathbf{0}$ & 0.55 & 0.50 & 0.55 & $\begin{array}{c}0.013 \pm \\
0.003\end{array}$ & $\begin{array}{c}15.18 \pm \\
0.86\end{array}$ & $4.36 \pm 0.47$ & 24.88 \\
\hline 5 & 0.55 & 0.56 & 0.60 & $\begin{array}{c}0.014 \pm \\
0.003\end{array}$ & $\begin{array}{c}14.20 \pm \\
0.58\end{array}$ & $4.97 \pm 0.42$ & 54.49 \\
\hline 10 & 0.61 & 0.60 & 0.60 & $\begin{array}{c}0.015 \pm \\
0.003\end{array}$ & $\begin{array}{c}13.40 \pm \\
0.20\end{array}$ & $5.58 \pm 0.17$ & 47.71 \\
\hline 15 & 0.66 & 0.61 & 0.61 & $\begin{array}{c}0.015 \pm \\
0.003\end{array}$ & $\begin{array}{c}12.92 \pm \\
0.65\end{array}$ & $6.03 \pm 0.63$ & 55.25 \\
\hline 20 & 0.70 & 0.62 & 0.69 & $\begin{array}{c}0.016 \pm \\
0.004\end{array}$ & $\begin{array}{c}12.10 \pm \\
0.84\end{array}$ & $6.89 \pm 0.90$ & 42.98 \\
\hline 30 & 0.83 & 0.66 & 0.75 & $\begin{array}{c}0.018 \pm \\
0.005\end{array}$ & $\begin{array}{c}10.92 \pm \\
1.29\end{array}$ & $8.62 \pm 2.01$ & 36.05 \\
\hline
\end{tabular}




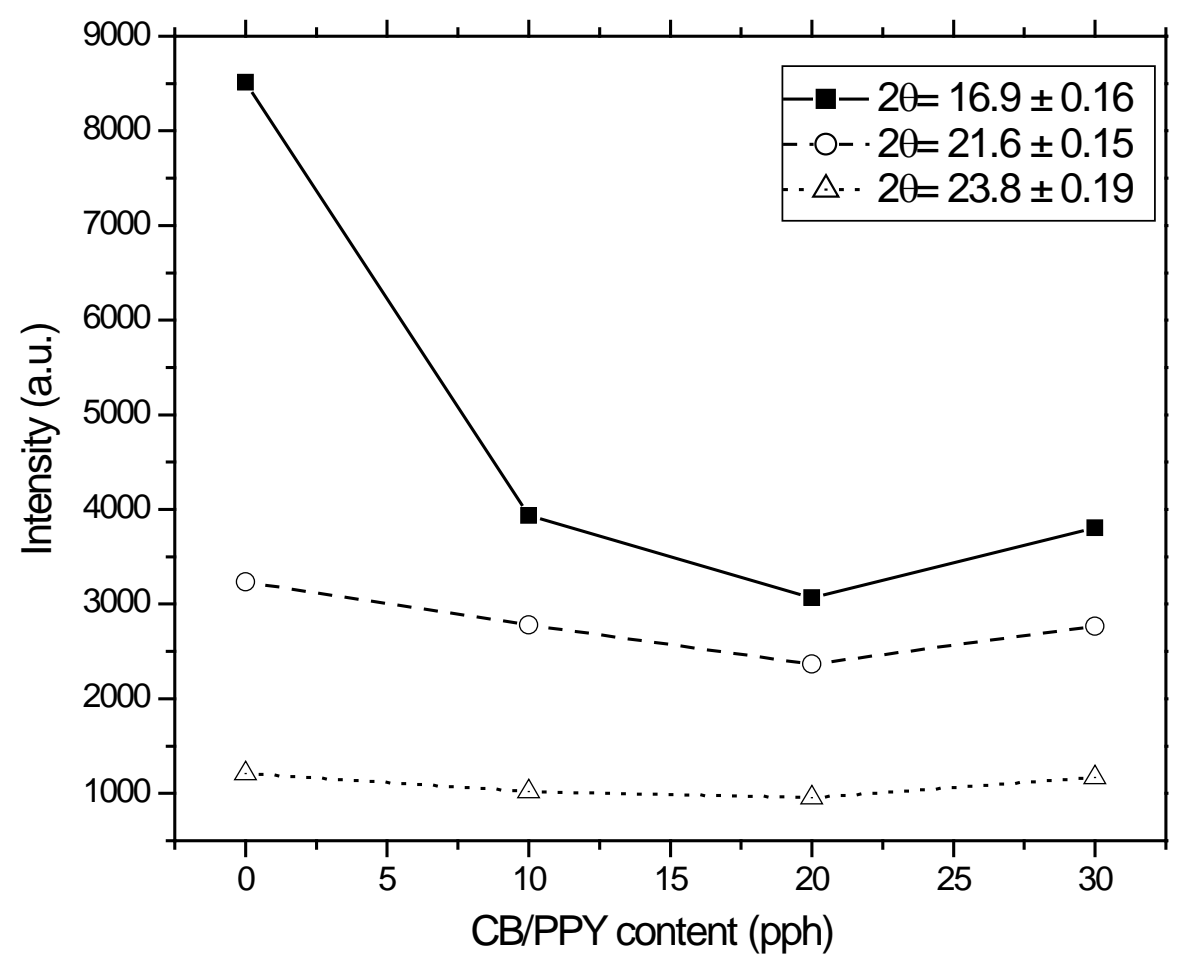

Figure (8) X-ray intensity vs. CB/PPy content (pph) for different composites

\section{Acknowledgment}

The authors would like to express their sincere appreciation and gratitude to Prof. Dr. G. M. Nasr (Physics Department, Faculty of Science, Cairo University, Giza, Egypt) for his support and great help.

\section{References}

1-Shi, X. M., Zhang J., Jin J. and Chen S. J. Nonisothermal crystallization and melting of ethylenevinylacetate copolymers with different vinyl acetate contents, eXPRESS Polym. Lett. 2 (9), 623-629 (2008).

2-Menczel, J. D. and Prime R. B.) Thermal Analysis of Polymers, Fundamentals and Applications, New York: Wiley (2009).

3-Kalogeras, I. M. and Brostow, W. Glass Transition Temperatures in Binary Polymer Blends. J Polym Sci Part B Polym Phys 47, 80- 95 (2009).

4-Brostow, W., Chiu, R., Kalogeras I. M. and Vassilikou-Dova, A. Prediction of glass transition temperatures: Binary blends and copolymers. Materials Letters 62 (17-18), 3152-3155 (2008).

5-Bower, D. I. An introduction to polymer physics, UK: Cambridge University Press, Cambridge (2002).
6-Ozkazanc, E. Polypyrrole/copper(II) acetylacetonate composites prepared by in situ chemical oxidative polymerization. Synth. Met.162 (11-12), 1016- 1023 (2012).

7-Reungurai, A., Promjun, A., Ouajai, W. P. and Ouajai, S. Synthesis of highly conductive polypyrrole nanoparticles via microemulsion polymerization. $J$ Met Mater Miner. 18 (2), 27-31 (2008).

8-Shokr, F.S. and Al-Gahtany, S.A. Dielectric properties of conductive polypyrrole/ethylene vinyl acetate copolymer blends. J Elastom Plast, 46 (5), 470 - 480 (2014).

9-Wang, B., Wang, X., Shi, Y., Tang, G., Tang, Q., Song, L. and Hu, Y. Effect of vinyl acetate content and electron beam irradiation on the flame retardancy, mechanical and thermal properties of intumescent flame retardant ethylene-vinyl acetate copolymer, Radiat Phys Chem 80 (11) 308- 315 (2012).

10-Bates, F. S., Cohen, R. E. and Argon, A. S. Dynamic mechanical properties of polystyrene containing microspherical inclusions of polybutadiene: Influence of domain boundaries and rubber molecular weight. Macromolecules.16 (7)1108 - 1114 (1983).

11-Schneider, H. A. Conformational Entropy Contributions to the Glass Temperature of Blends of 
Miscible Polymers. J Res Natl Inst Stand Technol 102 (2) 229-248 (1997).

12-Ahmed, R. M. Electrical conductivity and dielectric relaxation study of polyvinyl acetate/poly methyl methacrylate blends. Int J Mod Phys B 26,1250159 (2012).

13-Furukawa, G.T., Douglas, T. B., Mc Coskey, R. E. and Ginnings, D.C. Thermal properties of aluminum oxide from 0 to. $1200{ }^{\circ} \mathrm{K}, J$ Res NBS 57, 67, RP2694 (1956).

14-Greco, A., Gennaro, R. and Rizzo, M. Glass transition and cooperative rearranging regions in amorphous thermoplastic nanocomposites. Polym Int . 61 (8), 1326-1333 (2012).

15-Weeks, J. J. Melting Temperature and Change of Lamellar Thickness with Time for Bulk Polyethylene. J Res Natl Bur Stand. 67 A (5), 441451 (1963).

16-Kong, Y. and Hay, J.N. The enthalpy of fusion and degree of crystallinity of polymers as measured by DSC. Eur Polym J 39 (8), 1721-1727 (2003).

17-Benmesli, S. and Riahi, F. Dynamic mechanical and thermal properties of a chemically modified polypropylene/natural rubber thermoplastic elastomer blend. Polym Test. 36, 54-61 (2014).

18-Kim. J. H., Kim, J.Y., Lee, Y. M. and Kim, K.Y.) Properties and swelling characteristics of crosslinked poly (vinyl alcohol)/chitosan blend membrane. J Appl Polym Sci. 45, 1711-1717 (1992.

19-Reynolds, J. R., Wettermark, U. G., Worrell, G. A., Chen, C. S. Polypyrrole Films and Epoxy Laminates: Electrical Conductivity, Mechanical Integrity and Environmental Stability. Proc Am Chem Soc Div Polym Mat Sci Eng. 64, 267-268 (1991).

20-Sanches, E. A., Alves, S. F., Soares, J. C., Silva, A. M., Silva, C. G., Souza, S.M. and Frota, H. O. Nanostructured polypyrrole powder: a structural and morphological characterization. Journal of Nanomaterials 2015, ID129678 (2015).

21-Sakthivel S and Boopathi A, Synthesis and Characterization of Polypyrrole (PPY) Thin Film by Spin Coating Technique .J Chem \& Chem Sci 2014; 4: 150-155.

22-Abd El-Kader, F. H., Osman, W. H., Ragab, H. S., Shehap, A. M., Rizk, M. S., and Basha, M. A. F. (2004) Electrical and optical properties of polyvinyl alcohol thin films doped with metal salts. $J$ Polym Mater 21 (1), 49-60.

23-Hoang, T., Chinh, N. T., Trang, N. T. T., Hang, T. T. X., Thanhm, D. T. M., Hung, D.V., Chang-Sik Ha and Aufray, M. Effects of maleic anhydride grafted ethylene/vinyl acetate copolymer (EVA) on the properties of EVA/silica nanocomposites. Macromol Res 21 (11), 1210-1217 (2013).

24-Yoo, Hye-Min, Heo, Gun-Y. and Park, Soo-Jin Effect of crystallinity on the electrochemical properties of carbon black electrodes. Carbon Lett. 12 (4), 252- 255 (2011).

25-Bandla, S., Allahkarami, M. and Hanan, J.C. Out of Plane Orientation and Crystallinity of Biaxially Stretched Polyethylene Terephthalate. Powder Diffr. 29 (2), 123-126 (2014).

26-Kar, A., Datta, A. and Patra, A. Fabrication and optical properties of core/shell CdS/LaPO $4: \mathrm{Eu}$ nanorods. J Mater Chem. 20 (5), 916-922 (2010).

27-Deivanayaki, S., Ponnuswamy, V., Jayamurugan, P. and Ashokan, S. The structure and properties of Polypyrrole/Titanium dioxide nanospheres of various dopant percentages by chemical oxidation method. Elixir Polymer. 49B, 10182-10185 (2012).

28-Rathod, S. G., Bhajantri, R. F., Ravindrachary, V., Sheela, T., Pujari, P. K., Naik, J. and Poojary, B. Pressure sensitive dielectric properties of $\mathrm{TiO}_{2}$ doped PVA/CN-Li nanocomposite. $J$ Polym Res 22, 6 (2015).

29-Saleem, M., Fang, L., Ruan, H. B., Wu, F., Huang, Q. L., Xu, C. L. and Kong, C.Y. Effect of zinc acetate concentration on the structural and optical properties of $\mathrm{ZnO}$ thin films deposited by Sol-Gel method. Intl J Phy Sci 7 (23), 2971- 2979 (2012).

30-Hakeem, A., Shakoor, A., Irfan, M., Ali, I., Azharkhan, M., Naeem Ashiq, B. M., Ishaq, M. and Aziz, A. Synthesis and electrical properties of doped polypyrole with hexagonal ferrite. J Ovonic Res 10 (5) 149-156 (2014).

31-Mercy, A., Samuel Selvaraj, R., Milton Boaz, B., Anandhi, A. and Kanagadurai R. Synthesis, structural and optical characterization of cadmium sulphide nanoparticles. IJPAP; 51, 448 - 452 (2013). 